\title{
SHIP-BERTH LINK AND DEMURRAGE COSTS: EVALUATING DIFFERENT ALLOCATION POLICIES AND QUEUE PRIORITIES VIA SIMULATION
}

\author{
Peter Wanke
}

Received April 2010 / Accepted October 2010

\begin{abstract}
The ship-berth link is one of the most critical aspects to be managed at port operations. Until now, simulation models have considered the impact of queue priorities, such as size and type of ships, on waiting times. This research differentiates from previous studies not only by considering another variable - the demurrage cost for each type of ship -, but also by considering the possibility of different berth allocation policies. It reports on a simulation study on small Brazilian private container terminal, where different berth allocation policies and queue priorities have been tested. Results and further analyses conducted via MANOVA indicate that the demurrage cost ratio between large and small ships and the critical waiting time in queue, after which demurrage costs are charged, impact on the choice of most adequate combination of policies and priorities. The analysis presented in this paper may help port authorities in determining a more precise figure for total demurrage costs.
\end{abstract}

Keywords: ship-berth link, simulation, queue priority, berth allocation, demurrage costs, MANOVA.

\section{INTRODUCTION}

Several researchers have focused their work on studying the application of modelling techniques to port environment and the relationships between cost and service levels that might eventually arise. In the last decade, a growing number of studies dealing with ship-berth link planning (SBL) was produced (Imai et al., 2001, 2005). Traditionally, the SBL planning problem consists of assigning incoming ships to berthing positions, as well as scheduling quay-cranes, both relevant decisions to port operation management (Meisel \& Bierwirth, 2009).

If port authorities were able to plan and control SBL operations on a daily basis, given the characteristics of the ships and the market segments they serve, on a medium/long-term basis, they would be capable of planning adequately for future investments in berth expansion and would be also better prepared to deal with increasing competition (Ho \& Ho, 2006). This is important, because ship operators, to whom certain guarantees of berth availability are not

Center for Logistics Studies, COPPEAD Graduate Business School, Federal University of Rio de Janeiro (UFRJ), Rio de Janeiro, RJ, Brazil. E-mail: peter@coppead.ufrj.br 
given, may look for alternative ports in order to maintain high levels of efficiency (Dasgupta \& Gosh, 2000; Luo \& Grigalunas, 2003).

Within this context, the simulation of port operations may be an option to deal with these issues, as it contributes to evaluate port performance and generates different scenarios to help in decision-making (Dragovic et al., 2005; Duinkerken et al., 2006). In this paper, we focus on the analysis of ship waiting statistics and on total demurrage costs under different berth allocation policies and queue priorities, by means of a simulation model developed in ARENA. The model is fed with data from a case study on a private container terminal in Rio de Janeiro, conducted in 2009. Results are analyzed in terms of the most adequate combination of berth allocation policy and queue priority for a given set of critical levels of waiting times (after which demurrage costs are charged) and demurrage cost ratios between large and small ships.

The paper is organized as follows. In the next section, the major subsystems of port operations and the importance of SBL to port performance are presented. A particular emphasis is given to simulation as a research tool and to the impact of introducing priority on SBL performance. Then, the objectives of the study and the research questions are formalized, followed by another section where the methodology is detailed. Results are discussed and, at last, limitations and suggestions for future research are also addressed.

\section{LITERATURE REVIEW}

Casaca (2005) presented a comprehensive framework of port industry operations, describing in details their three major subsystems: the shipside interface or berthing area, the container yard, and the gates. Her conceptual scheme makes clear that port operations are complex by nature and, therefore, require modelling techniques, such as simulation, genetic algorithms, and nonlinear programming, in order to help port authorities in different aspects of decision-making. Casaca's framework (2005) is used in this research to map and organize different studies according to their major objectives, modelling techniques, subsystems, and decisions.

\begin{tabular}{|c|}
\hline Seaside \\
\hline Berthing Area \\
\hline Container Yard \\
\hline Gates (Road/Rail) \\
\hline
\end{tabular}

Figure 1 - Casaca's (2005) framework.

Similarly to Casaca (2005), Chang (2005) divided a container terminal into three subsystems and modelled different patterns involving berth operations. He did so to test possible queuing scenarios at the container yard, driven by the fact that most shipping companies have recently begun to operate very large containerships. Using simulation software to construct different models of berth operations and examining possible scenarios at the container yard, Tu \& Chang 
(2006) found that shipside operations might be considerably accountable for delays at the container yard.

Parola \& Sciomachen (2005) presented a simulation model in order to analyze how to face the impact of sea traffic growth on the land infrastructure. More precisely, the authors studied and proposed alternatives to deal with the impact on the saturation degree of the railway lines and on the congestion level of truck gates. Kim et al. (2003) suggested a dynamic programming model for the arrivals of trucks. Several sequencing rules were also compared via simulation. According to the authors, the shortest processing time rule showed a robust and high level performance.

Duinkerken et al. (2006) presented a comparison among three transportation systems for the overland transport of containers between terminals. In parallel, Ottjes et al. (2006) proposed a generic simulation model structure for the design and evaluation of multi-terminal systems for container handling. In both studies, the experiments conducted gave insight into the importance of the different characteristics of the transport systems and their interaction with the handling equipment.

According to Legato \& Mazza (2001), the competitiveness of a port is especially measured in terms of an adequate service level offered to shipping companies. Ho \& Ho (2006) indicate that a primary goal for port authorities is to reduce the waiting time of ships from the time they arrive at the port to the leaving instant, by means of a better management of current resources. Eventually, investments in capacity expansion may be needed, implying large capital expenditures. In this sense, a closer look at the SBL is deemed necessary (Ho \& Ho, 2006). This link is not only accountable for a substantial part of the necessary investment to build a port, but also for the total waiting time in queue until (un)loading operations begin.

The SBL operation has been variously referred to as berth planning system (Legato \& Mazza, 2001), berth allocation planning (Nishimura et al., 2001), berth allocation problem (Meisel \& Bierwirth, 2009), and berth-crane operations (Canonaco et al., 2008). In general terms, it becomes clear that the major task of the SBL operation is to allocate a limited number of berths among incoming ships. The choice of berthing one ship rather than another into one specific berth can result in a too long distance from the location point of its containers in the yard, generating cross-effects in terms of delays, not only at the container yard operations, but also at the berthing queue (Meisel \& Bierwirth, 2009).

Another common feature of the SBL operation is the necessity to deal with resource limitations and physical constraints (Nishimura et al., 2001). The limited number of berths and quay cranes constraints the service capacity of ports and terminals, frequently leading to a trade-off between investments in fixed assets and total demurrage costs. In such cases, the use of simulation as a planning tool has been of growing importance to find a balance between queue priorities and the possibility to postpone such investments.

Dragovic et al. (2005), who have reported on several different simulation models with respect to port operations, particularly examined the impact of introducing priority for a certain class of ships on SBL performance. One of their simulation models indicated that assigning priority to 
smaller ships would lead to an improvement of the main operational parameters, like the average number of ships in queue and the average time a ship spends in queue. One can easily understand the crucial role that the time spent in queue plays in reducing the total waiting time of ships from the time they arrive at the port to the leaving instant. The path to a lean port environment should involve some fundamentals of operations management (Casaca, 2005), like, for instance, an in-depth study on queue priorities and berth allocation policies.

As pointed out by Asperen et al. (2003), priority rules are expected to reduce the waiting costs of high-priority ships. In their study, a simple priority scheme was considered with two priority classes (high and low), where the large ships get high priority and the small ones, low. Applying priority rules, the percentage of high-priority ships was reduced, while the percentage of low-priority ships that had to wait was increased. However, whether priority rules reduce total demurrage costs, and to what extent, it depends on how much more expensive an idle high-priority ship, compared to a low-priority, is. This still remains to be tested. According to Dragovic et al. (2005), as cost is a key measure in the selection of alternative strategies to the SBL problem, further research needs to incorporate a cost analysis in order to identify the most appropriate combination of berth allocation policies and queue priorities in a given context.

\section{RESEARCH MOTIVATIONS, OBJECTIVES, AND QUESTIONS}

Transportation has increased in importance for the economy and firms in the globalization scenario. In order to support trade oriented economic development, port authorities have increasingly been under pressure to improve port efficiency, ensuring that port services are provided on an internationally competitive basis. There is a consensus that ports form a vital link in the overall trading chain by contributing to a nation's international competitiveness (Tongzon, 1989; Chin \& Tongzon, 1998). In Brazil, one of the so-called "emerging countries" or "BRICs" (Wilson \& Purushothaman, 2003) - acronym that stands for Brazil, Russia, India, and China - exports in nominal prices more than doubled in the period between 2002 and 2008, reaching almost US\$ 200 bn (Fleury \& Hijjar, 2008).

Port congestion arises when port capacity is insufficient to cope with the traffic arriving at the port (Alderton, 2008). It is not a new problem and can occur at any port if there is a sudden upsurge in demand, for example. In fact, several empirical evidences suggests that Brazilian ports are running short in capacity and that ships are experimenting increasing waiting times in queue before mooring in a given berth (Sá, 2009). When this happens, demurrage costs occur. Demurrage costs are the waiting charges levied by ship-owners if their ships are not loaded or unloaded within a specified time.

In this paper, we consider a simulation case study on a Brazilian private container terminal as the starting point to address whether priority rules and berth allocation policies reduce total demurrage costs and to what extent. Based on the literature review, the following questions were set for this simulation study. The first set of three questions relates to the quantification of the 
impacts of berth allocation policies and queue priorities on the time a ship spends in queue. These questions are:

1) Considering the port system as a whole and each ship that periodically visits the port, what is the impact of different berth allocation policies and queue priorities on queue waiting times?

2) What are the signs of the relationship among these variables?

3) What is the most relevant main effect: berth allocation policy or queue priority?

In this study, four different berth allocation policies were considered. They are listed next.

- "Dedicated berths according to ship type": that is, one berth serves exclusively small or large ships;

- "Single queue distributes ships to the first available berth": in this case, all berths serve both ship types (large and small). Ships are held in one single queue before they are directed to the first available berth;

- "Ships are allocated to the berth with the smallest expected queue size": different from the last policy, there is no single queue holding ships until a berth is available; ships enter the queue with the smallest size. All berths serve all ship types;

- "Ships are allocated to the berth with the shortest expected queue time": this policy differs from the previous one, because, here, ships enter the queue with the shortest expected time to begin berthing. It is based on the sum of the expected processing time of ships already waiting in queue.

In each policy above, eight different queue disciplines or priorities were considered (Hansen, 1972; Silberholz et al., 1991). These disciplines decide which ship in queue is going to be served next, at the moment a berth becomes available. They are given as follows:

- "Longest processing time": under this priority, the ship with the longest processing time is served first when a berth is available;

- "Shortest processing time": opposite to the one above;

- "Largest number of scheduled ship arrivals per year": under this priority, the ship with the largest number of scheduled visits per year is served first;

- "Smallest number of scheduled ship arrivals per year": opposite to the one above;

- "FIFO" (first-in, first-out): a classic and well-known queue discipline (Nahmias, 2001);

- "LIFO" (last-in, first-out): another classic discipline, opposite to the one above;

- "Largest ship size": under this priority, the largest ship is served first when a berth is vacant;

- "Smallest ship size": opposite to the one above. 
The second set of questions is related to the formalization of elements to support the strategic positioning of port authorities. These new questions are an unfolding of the results obtained for the three previous questions, in light of different demurrage penalties for different ship types. These secondary questions are:

4) What are the apparent contradictions between analyzing the SBL operation as a whole and analyzing the SBL operation as a weighted sum of each one of the ship types, in terms of demurrage costs and waiting times in queue?

5) Considering the port authorities' perspective, what is, in terms of berth allocation policy and queue priority, the most adequate strategic positioning, which minimizes the total demurrage costs and, at the same time, observes different critical levels of waiting times in queue?

\section{METHODOLOGY}

In order to address the previously mentioned questions, a series of controlled experiments with two factors (berth allocation policy and queue priority) and several levels was developed and conducted, so as to assess their impact on the time a ship spends in queue and its major statistics (mean and variance). For this purpose, the SBL operation of a Brazilian private container terminal was modeled. MULTIRIO is a small-sized container terminal, with only two berths and storage capacity of 8,000 TEUs, in Rio de Janeiro. The layout of this container terminal is depicted in Figure 2.

The possible alternatives for the SBL operation are illustrated in Figure 3 by means of different flowcharts. These flowcharts were modeled in ARENA 9.0, a well-established simulation tool for discrete events (Chung, 2004). They basically indicate the same sequence of activities and decisions, differing only by the factors tested. In general terms, the ship service begins when the ship arrives at the port. Depending on congestion and priority assigned, the arriving ship may have to wait until a berth is available. After berthing, containers are unloaded (loaded) from (on) the ship. Finally, when the service is completed, the ship leaves the port. Figure 4 presents a screen of one of the main SBL models developed in ARENA.

For each one of the combinations of berth allocation policies and queue priorities, 30 replications of 1000 days of operations were conducted. Statistics on the waiting time in queue, for the system as a whole and for each ship that periodically berths at the port, were collected. It is worthwhile mentioning, as a methodological note, that the SBL model focused on ships that visit the port at least two times per year. In 2009, from 23 ships, 14 met this criterion. They were the objects of analysis of this case study. The dependent and independent variables of the model are presented in Table 1, which also shows their scales, dimensions, and operational definitions.

The control variables, that is, the ones that had no variation for all combinations, were based on data collected in this case study. They are the mean interarrival times and the mean processing times at berth for each ship. It is also assumed that the port resources (equipments, capacities, and 


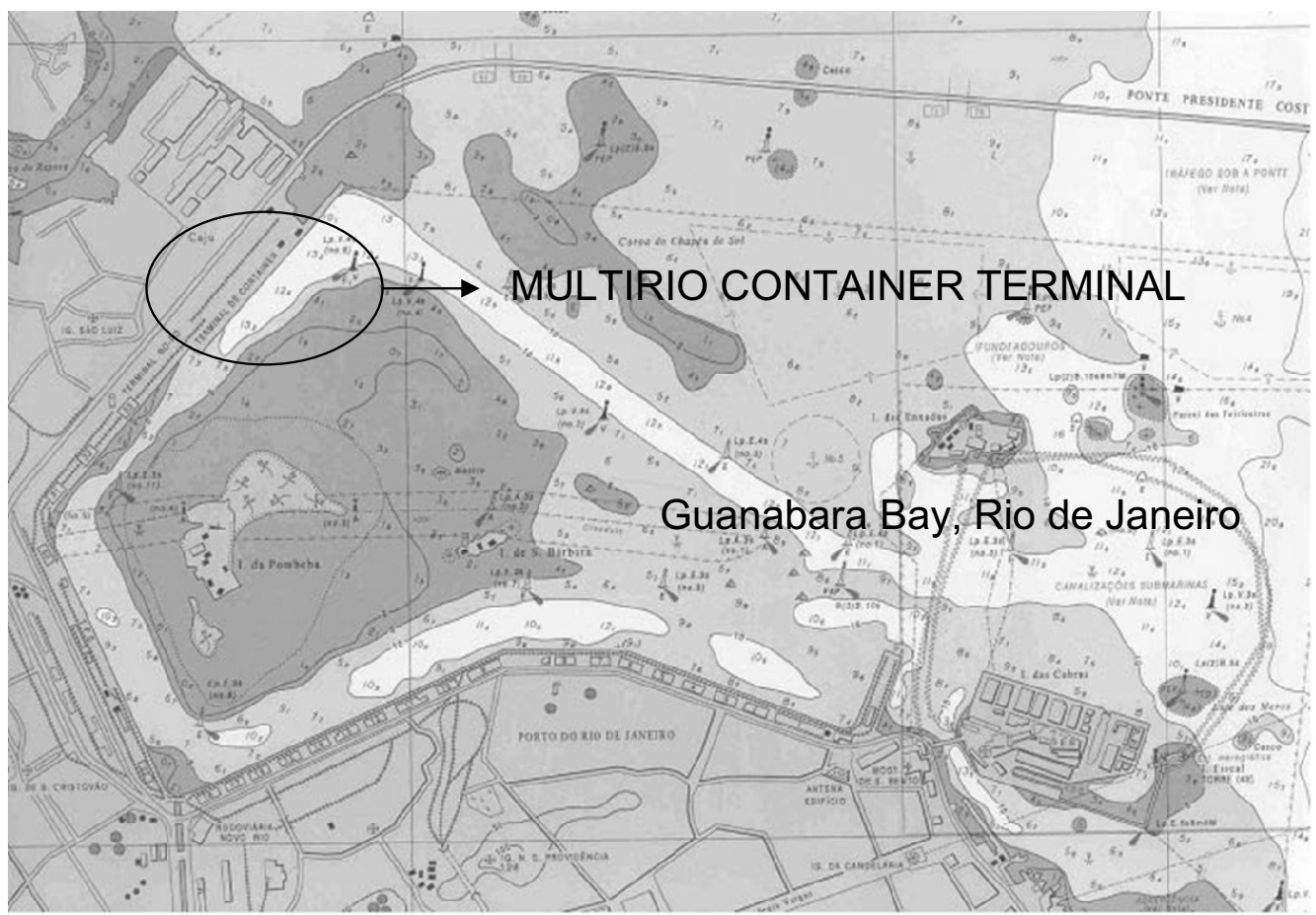

Figure 2 - Layout of the small container terminal.

(1) Dedicated berths according to ship size

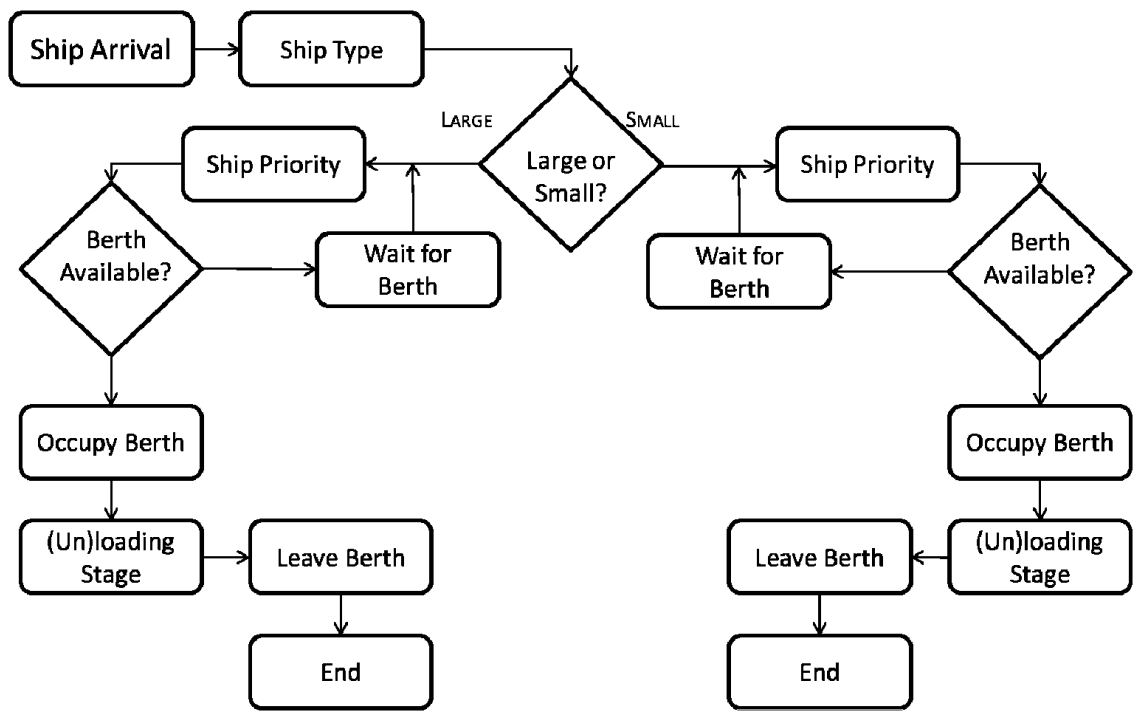

Figure 3 - Process flowcharts. (See continuation in next page). 
(2) Single queue distributes ships to first available berth

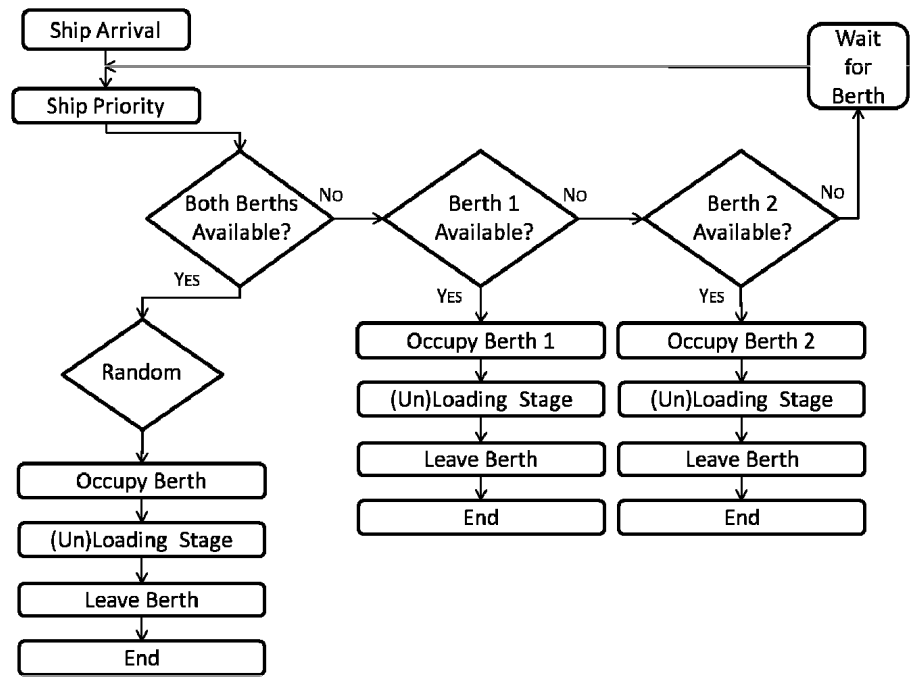

(3/4) Ships allocated to berth with smallest expected queue size or time (Q1 and Q2)

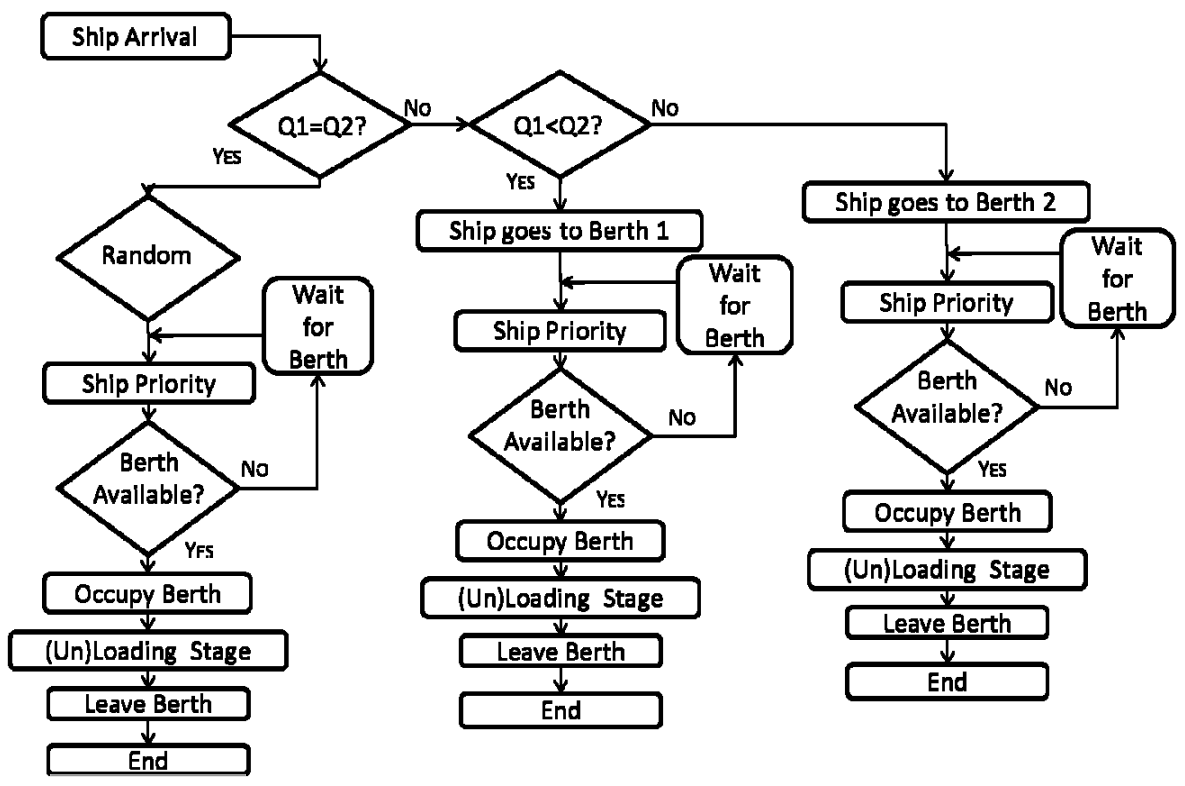

Figure 3 - (continuation) - Process flowcharts.

so on) not considered in the scope of the SBL operation modeled in ARENA did not influence the statistics collected for the time spent in queue by each ship.

The interarrival times for each ship were assumed to be exponentially distributed and their means are given in Table 2. According to Dragovic et al. (2005), the interarrival time distribution is a basic input parameter that has to be presumed or inferred from observed data. In literature, 


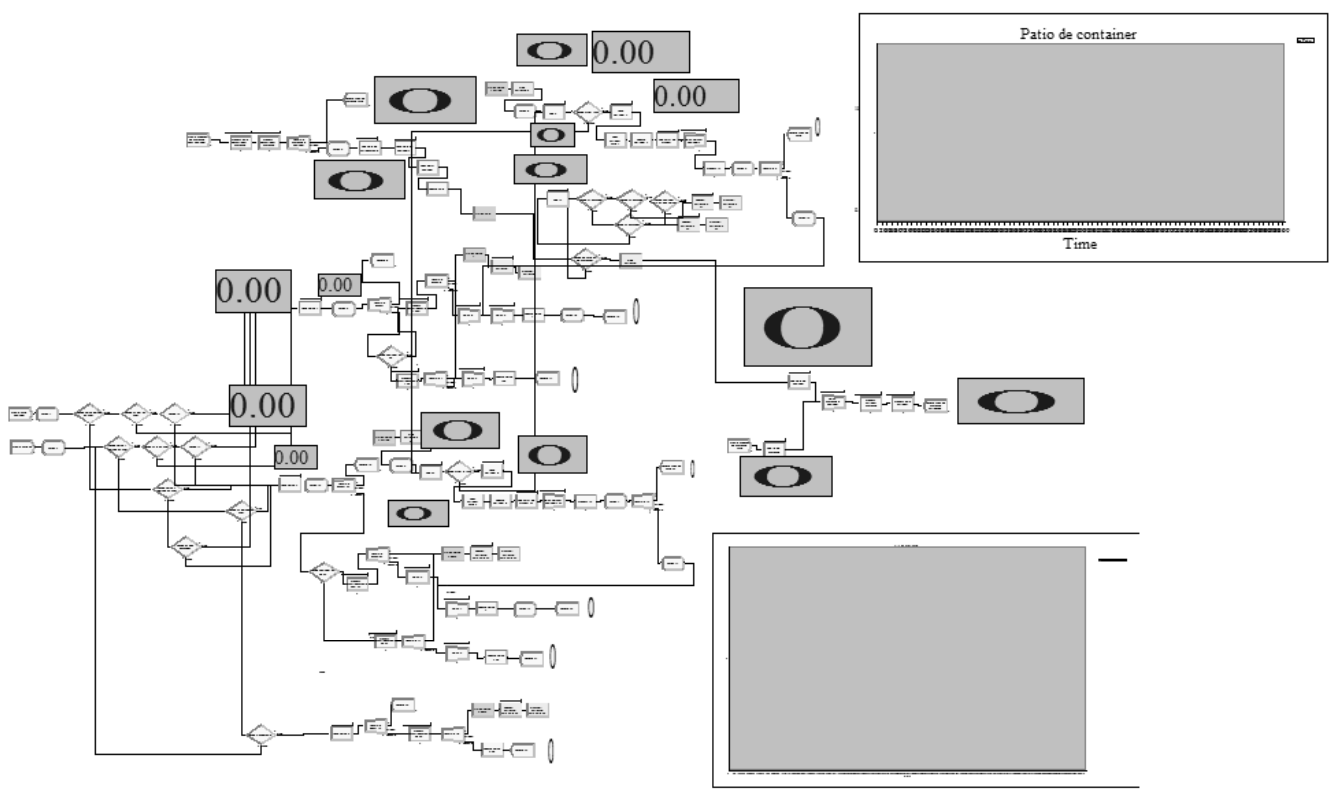

Figure 4 - Dedicated berths model.

the most commonly assumed distributions are the exponential (Demirci, 2003; Pachakis \& Kiremidjian, 2003), the negative exponential (Shabayek \& Yeung, 2002), and Weibull distribution (Tahar \& Hussain, 2000).

The processing times at berth for each ship were assumed to be normally distributed and their means are also given in Table 2. Four sublevels $(0,0.1,0.2$, and 0.4$)$ of their coefficients of variation were tested under each combination. Several studies indicate that empirical distributions of lifts per ship adhere to normal distribution (Dragovic et al., 2005). Even when real data are not available to justify the use of a particular distribution, the number of lifts per ship can be reasonably approximated by the normal random variable (Pachakis \& Kiremidjian, 2003).

Since the container terminal is relatively small, with only two berths, another simplification in the SBL model was taken. That is, the choice of anchoring one ship into one specific berth, rather than another, was supposed not to impact on the distance between the ship and the location point of its containers in the yard. Finally, it was also considered that the remainder port resources, which were not modeled in ARENA, did not impact on the time spent in queue by each ship.

Multivariate Analysis of Variance (MANOVA) was the method used to analyze the results. It was considered to be appropriate to control for a given covariate in experimental research (Tabachnick \& Fidell, 2001). According to Hair et al. (1998), it is advisable that the covariate is strongly correlated to the dependent variables (mean and variance of waiting times in queue), but not to the independent variables (berth allocation policies and queue priorities), which constitute the factors of this study. The selected covariate was the coefficient of variation of processing times. The maximum acceptable significance level was 0.05 . 
Table 1 - Simulation variables.

\begin{tabular}{|c|c|c|c|c|}
\hline Variable & Type & Scale & Dimension & Operational definition \\
\hline $\begin{array}{l}\text { Average waiting } \\
\text { time in queue for } \\
\text { each ship and the } \\
\text { whole system }\end{array}$ & Dependent & Metric & Hours & $\begin{array}{l}\text { Computed across } \\
900 \text { days at each one } \\
\text { of the } 30 \text { replications }\end{array}$ \\
\hline $\begin{array}{l}\text { Variance of waiting } \\
\text { time in queue for } \\
\text { each ship and the } \\
\text { whole system }\end{array}$ & Dependent & Metric & Hours $^{2}$ & $\begin{array}{l}\text { Computed across } \\
900 \text { days at each one } \\
\text { of the } 30 \text { replications }\end{array}$ \\
\hline $\begin{array}{l}\text { Berth allocation } \\
\text { policy }\end{array}$ & Independent & Nominal & $\begin{array}{l}\text { 1. Dedicated berths } \\
\text { per ship type (size - } \\
\text { large/small) } \\
\text { 2. Single queue } \\
\text { distributes ships to } \\
\text { first available berth } \\
\text { 3. Ships allocated to } \\
\text { berth with smallest } \\
\text { queue size } \\
\text { 4. Ships allocated to } \\
\text { berth with smallest } \\
\text { queue time }\end{array}$ & $\begin{array}{l}\text { Main effect } \\
\text { to be tested }\end{array}$ \\
\hline Queue priority & Independent & Nominal & $\begin{array}{l}\text { a. Largest } \\
\text { service time } \\
\text { b. Smallest } \\
\text { service time } \\
\text { c. Largest \# of } \\
\text { visits/year } \\
\text { d. Smallest \# of } \\
\text { visits/year } \\
\text { e. FIFO } \\
\text { f. LIFO } \\
\text { g. Largest ship size } \\
\text { h. Smallest ship size }\end{array}$ & $\begin{array}{l}\text { Main effect } \\
\text { to be tested }\end{array}$ \\
\hline $\begin{array}{l}\text { Coefficient of } \\
\text { variation of } \\
\text { processing time }\end{array}$ & Independent & Metric & $\begin{array}{l}\text { Four levels: } \\
0,0.1,0.2 \text {, and } 0.4\end{array}$ & Control variable \\
\hline
\end{tabular}

It is important to observe that this study differentiates itself from previous efforts reported in literature not only because it experimentally assesses the signs of the relationships between berth allocation policies and queue priorities, in terms of the means and variances of waiting times in queue, but also because it quantifies their main effects by means of multivariate statistical analyses, controlling them by the coefficient of variation of processing time at berth. The case study 
Table 2 - Control variables.

\begin{tabular}{|c|c|c|c|c|c|}
\hline $\begin{array}{c}\text { Ship } \\
\#\end{array}$ & $\begin{array}{c}\text { Ship } \\
\text { size } \\
\text { (TEUs) }\end{array}$ & $\begin{array}{c}\text { Ship type* } \\
(\text { small if TEUs } \\
\leq 1,700)\end{array}$ & $\begin{array}{c}\text { Expected } \\
\text { processing time } \\
\text { (hours) }\end{array}$ & $\begin{array}{c}\text { Expected } \\
\text { number arrivals } \\
\text { per year }\end{array}$ & $\begin{array}{c}\text { Interarrival } \\
\text { time } \\
\text { (hours) }\end{array}$ \\
\hline 1 & 1,000 & Small & 7.53 & 77 & 114 \\
\hline 2 & 1,250 & Small & 8.34 & 50 & 175 \\
\hline 3 & 1,500 & Small & 10.27 & 14 & 626 \\
\hline 4 & 1,700 & Small & 10.02 & 70 & 125 \\
\hline 5 & 1,750 & Large & 8.21 & 20 & 438 \\
\hline 6 & 1,800 & Large & 10.54 & 64 & 137 \\
\hline 7 & 2,000 & Large & 14.09 & 54 & 162 \\
\hline 8 & 2,000 & Large & 8.65 & 121 & 72 \\
\hline 9 & 3,000 & Large & 19.50 & 31 & 283 \\
\hline 10 & 3,250 & Large & 25.32 & 4 & 2,190 \\
\hline 11 & 3,400 & Large & 27.01 & 5 & 1,752 \\
\hline 12 & 3,700 & Large & 26.80 & 22 & 398 \\
\hline 13 & 3,800 & Large & 43.28 & 5 & 1,752 \\
\hline 14 & 4,000 & Large & 55.21 & 4 & 2,190 \\
\hline
\end{tabular}

*Ship type was arbitrarily classified by port authorities.

on a two-berth container terminal and underlying assumptions serve the purpose of exploring in depth, by means of a simplified simulation model, the influence of different berth allocation policies and queue priorities in the SBL operation.

\section{SIMULATION RESULTS}

MANOVA was performed with two dependent variables related to the mean and the variance of waiting times in queue for each one of the 14 ships and the system as a whole. In total, 3,840 observations were considered: 30 replications per factor combination $\times 4$ berth allocation policies $\times 8$ queue priorities $\times 4$ levels of coefficient of variation of processing times. As mentioned before, each replication consisted of a run length of 1,000 days of operation, from which the first 100 days were discarded (warm-up period). No outlier observations were detected among cells at the 0.0001 significance level. Satisfactory results were also obtained for normality, homogeneity of variance-covariance matrices, linearity, and multicollinearity assumption tests.

According to Wilks' lambda values (Hair et al., 1998), the combined dependent variables (mean and variance of waiting times in queue per ship) are significantly related with the following independent variables: berth allocation policy $(F=413.599, p<0.001)$, queue priority $(F=$ 48.012, $p<0.001)$, and coefficient of variation of processing time $(F=29.394, p<0.001)$. These results indicate strong relationships between dependent and independent variables, with a partial association power $\left(\eta^{2}\right)$ equal to 1.000 for both berth allocation policy and queue priority. 
The estimated parameters for the impacts of berth allocation policy and queue priority, controlled for the coefficient of variation of processing times, are presented in Tables 3 and 4 (addressing research questions 1 and 2). "Ships are allocated to the berth with the shortest expected queue time" and "Smallest ship size" are, respectively, the reference levels for berth allocation policy and queue priority. The coefficients represent the marginal impact of other berth allocation policies ("Dedicated berths according to ship size", "Single queue distributes ships to first available berth", and "Ships are allocated to the berth with the smallest expected queue size") and queue priorities ("Longest processing time", "Shortest processing time", "Largest number of scheduled ship arrivals per year", "Smallest number of scheduled ship arrivals per year", "FIFO", "LIFO", and "Largest ship size") altogether with the coefficient of variation of processing time. The intercept represents the marginal estimated means for the reference levels. Table 3 also indicates the values of $F$ and adjusted $\mathrm{R}^{2}$ statistics for the models that are associated to each dependent variable.

The signs presented in Table 3 for the expected waiting time in queue (whole system) corroborate the results found by Dragovic et al. (2005), according to which assigning priority to smaller ships would lead to an improvement of the average time a ship spends in port. The queue priorities "Smallest ship size" and "Shortest processing time" present, respectively, null or negligible impact on the average waiting time in queue when compared to other disciplines. The same occurs under "Largest number of ship arrivals" per year. Considering this priority, one can easily realize ( $c f$. Table 2 ) that the ship size is positively correlated to its processing time $(0.47$, $p<0.05$ ) and that the ship size is negatively correlated, though weakly, to the number of arrivals per year $(-0.333, p=0.157)$. On its turn, the ship processing time is strongly and negatively correlated to the number of arrivals per year $(-0.619, p<0.01)$. These three queue priorities are, therefore, related to different aspects of the same operational characteristic: smaller size, shorter processing time, and higher number of arrivals per year.

Considering each decision, the relative impact on each dependent variable is indicated by the modulus of the coefficients ( $c f$. Tables 3 and 4). However, the draw of further conclusions depends not only on the aggregation level of the analysis (whole system or a given ship), but also on the specific combination among the berth allocation policy, the queue priority, and the coefficient of variation of processing time.

For example, analyzing the whole system, if berths are dedicated according to ship size, the berth allocation policy will present the highest positive impact on the average waiting time in queue (4.78), followed, in sequence, by the coefficient of variation of service time (1.06) and, then, by the assignment of priority to ships with the longest processing time (0.57). Results should be analyzed in a similar way for all other independent variables.

As exemplified, this analysis provides an overview of the structure of the average waiting time in queue for the system as a whole. However, specifics of small and large ships related to their sensitivity to variations on processing times, demurrage cost ratios, and number of arrivals per year are not yet captured. 


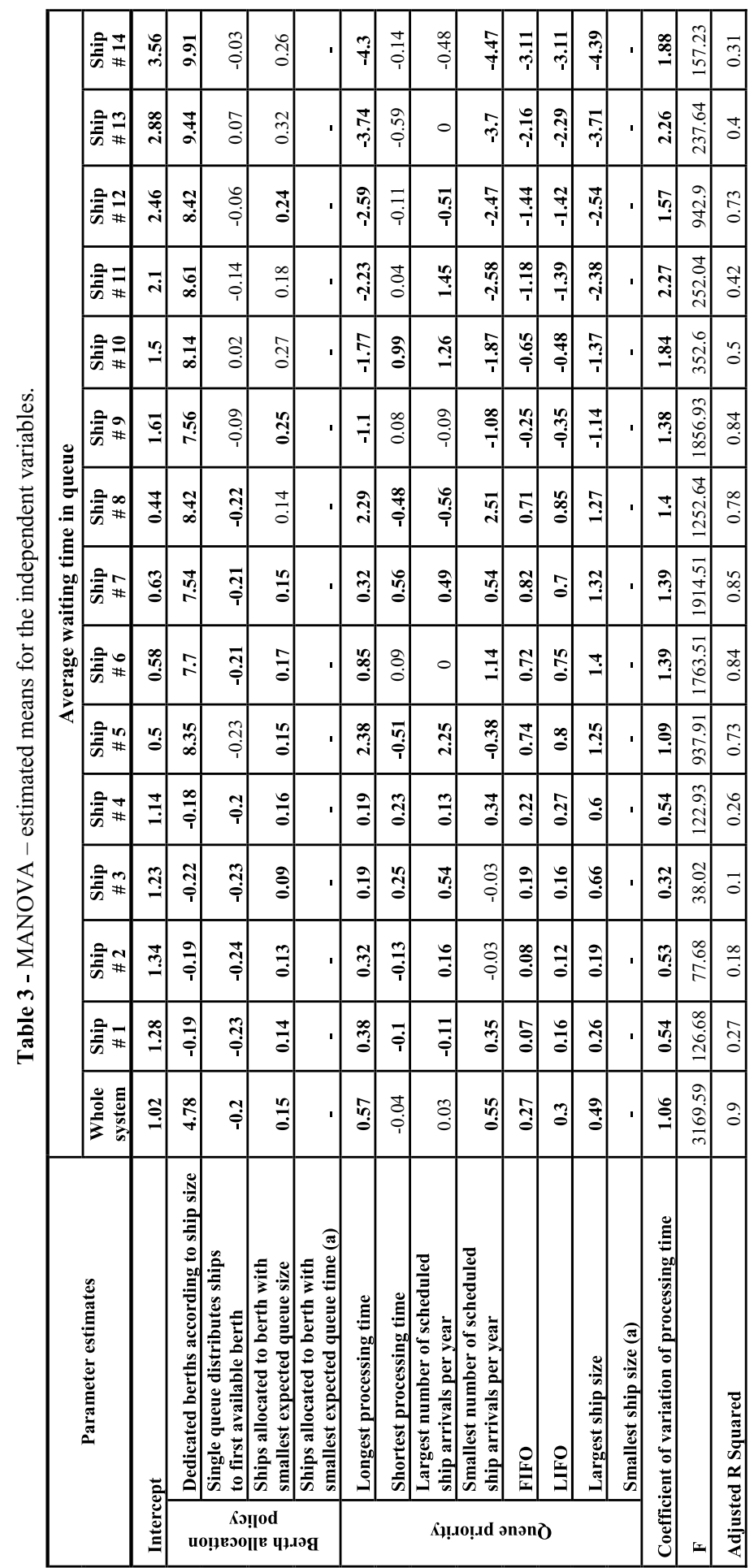




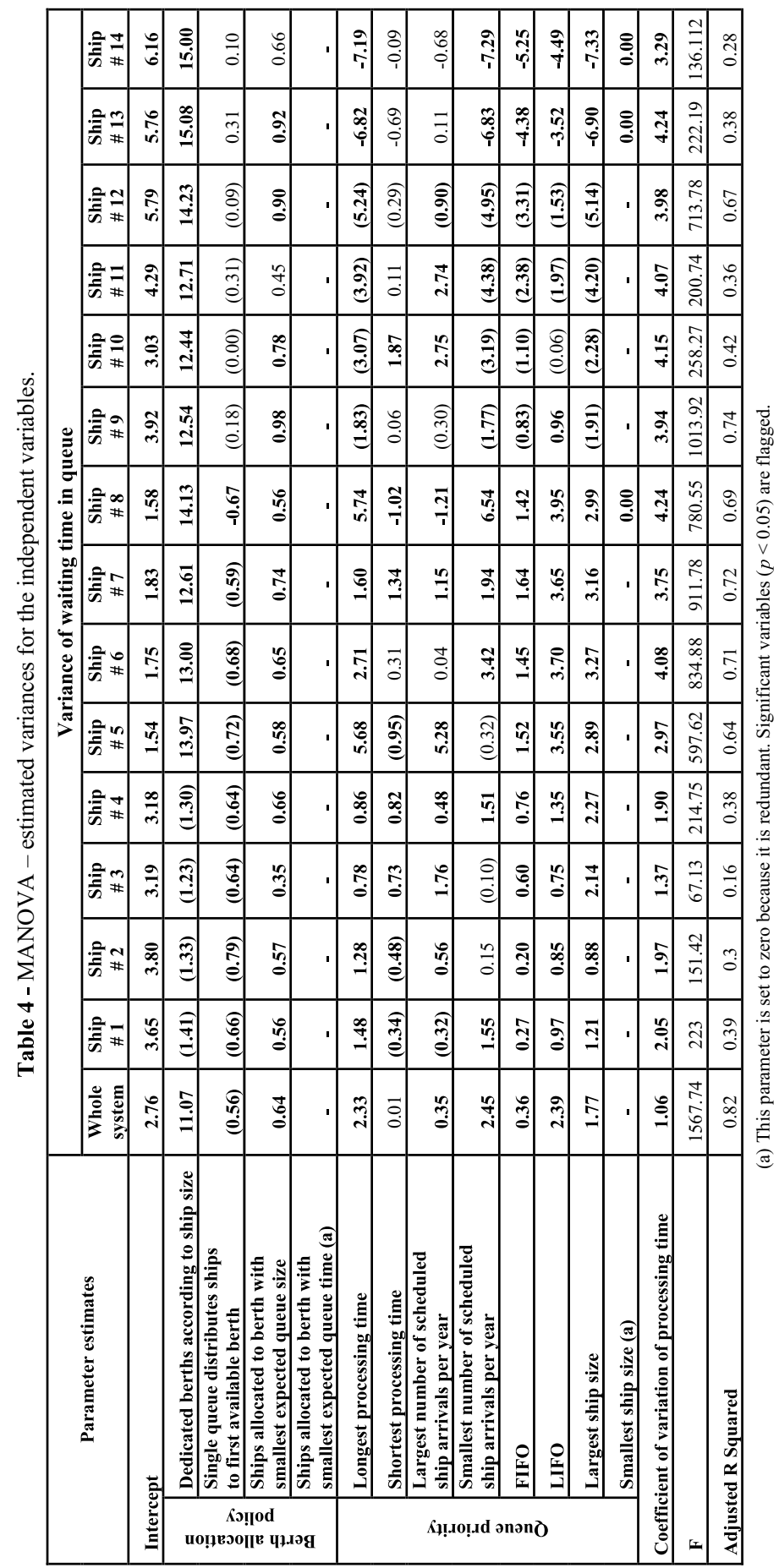


Analyzing Table 3, it is possible to affirm that small ships would benefit more from "Dedicated berths according to ship size" or "Single queue distributes ships to the first available berth" policies. Small ships are also less impacted by the coefficient of variation of processing times. With respect to queue priorities, it seems to be a balance between "Shortest processing time" and "Smallest ship size" in terms of their impact on the average waiting time.

On the other hand, when large ships are considered, one can realize that they would benefit more from "Single queue distributes ships to the first available berth" or "Ships are allocated to the berth with the shortest expected queue time" policies. As regards the assignment of a given queue priority, however, the picture is not so clear. It is also possible to affirm that large ships are more impacted than small ones by the coefficient of variation of processing times.

Figure 5 presents the marginal expected values of the average waiting time in queue for each ship at each one of the combinations between berth allocation policies and queue priorities. These expected values were evaluated at the mean level of the coefficient of variation of processing time $(0.175)$ and calculated based on the coefficients in Table 3 . It is clear that these countervailing forces within berth allocation policies and queue priorities for each ship should be taken together into account. More precisely, they should be weighted not only by the number of arrivals per year, but also by the demurrage cost of each ship, in order to determine what combination would lead, in fact, to the smallest total demurrage cost for the whole system.

However, an analysis simply based on the marginal expected values of the average waiting time in queue for each ship may not reveal the full picture about total demurrage costs. Therefore, a probabilistic analysis is deemed necessary. Figure 6 presents the marginal expected values for the variance of the waiting time in queue for each ship at each one of the combinations of berth allocation policies and queue priorities. These values were also evaluated at the mean level of the coefficient of variation of processing time and calculated based on the coefficients in Table 3 .

Supposing that the waiting times in queue for each ship $(W q)$ are gamma-distributed variables, it is possible to determine, for each combination of berth allocation policy and queue priority, the expected demurrage time (in hours) after a critical waiting time in queue ( $W q_{-}$critical, in hours). Weighting this expected demurrage time $\left(E\left(W q / W q>W q_{-}\right.\right.$critical $\left.)\right)$by the number of arrivals per year $(N A)$ and the demurrage cost per hour (c) of each one of the $i$ ships, and, then, summing the 14 ships up, one gets the total demurrage cost $(T D C)$, per year, for a given combination. More precisely:

$$
T D C=\sum_{i=1}^{14} N A_{i} \cdot c_{i} \cdot E\left(W q_{i} / W q_{i}>W q_{\text {_critical }}\right),
$$

per year, for a given combination of berth allocation policy and queue priority. The best combination is the one that leads to the smallest $T D C$.

Before proceeding with the discussion on how this expected demurrage time can be determined based on Table 3, some additional considerations on the choice of the gamma assumption for waiting times in queue must be made first. The choice of the gamma distribution is due to its 

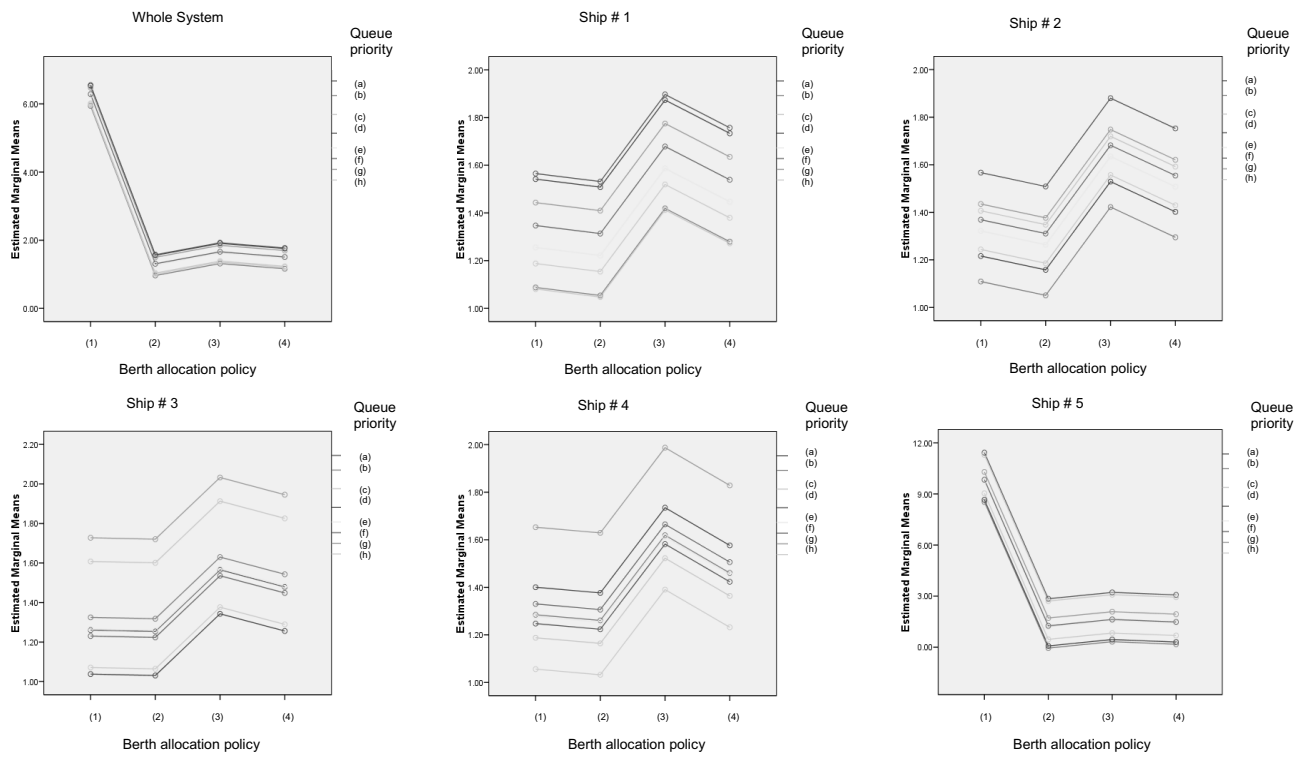

Queue
priority
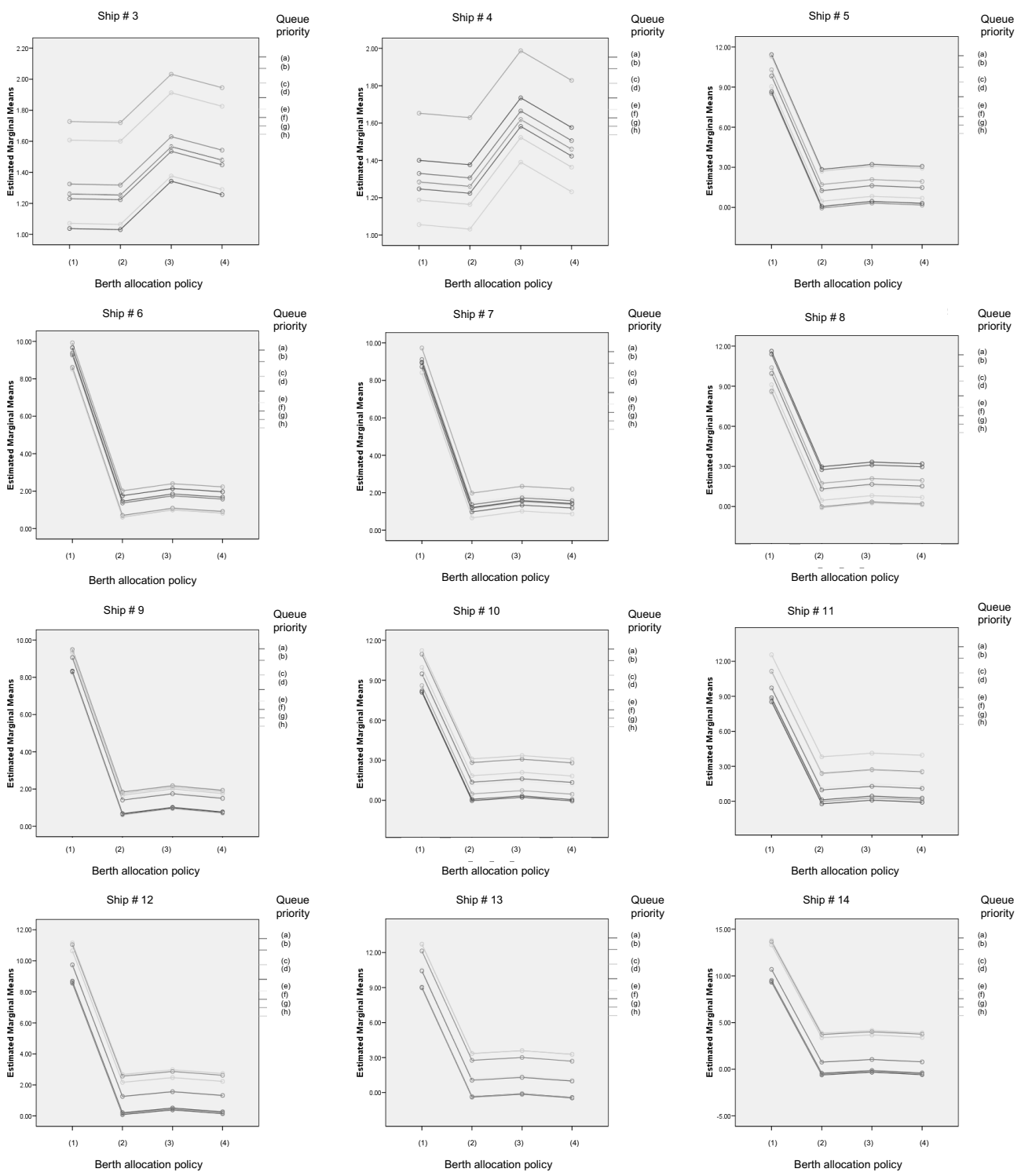

Figure 5 - Estimated marginal means for the average waiting time in queue. 

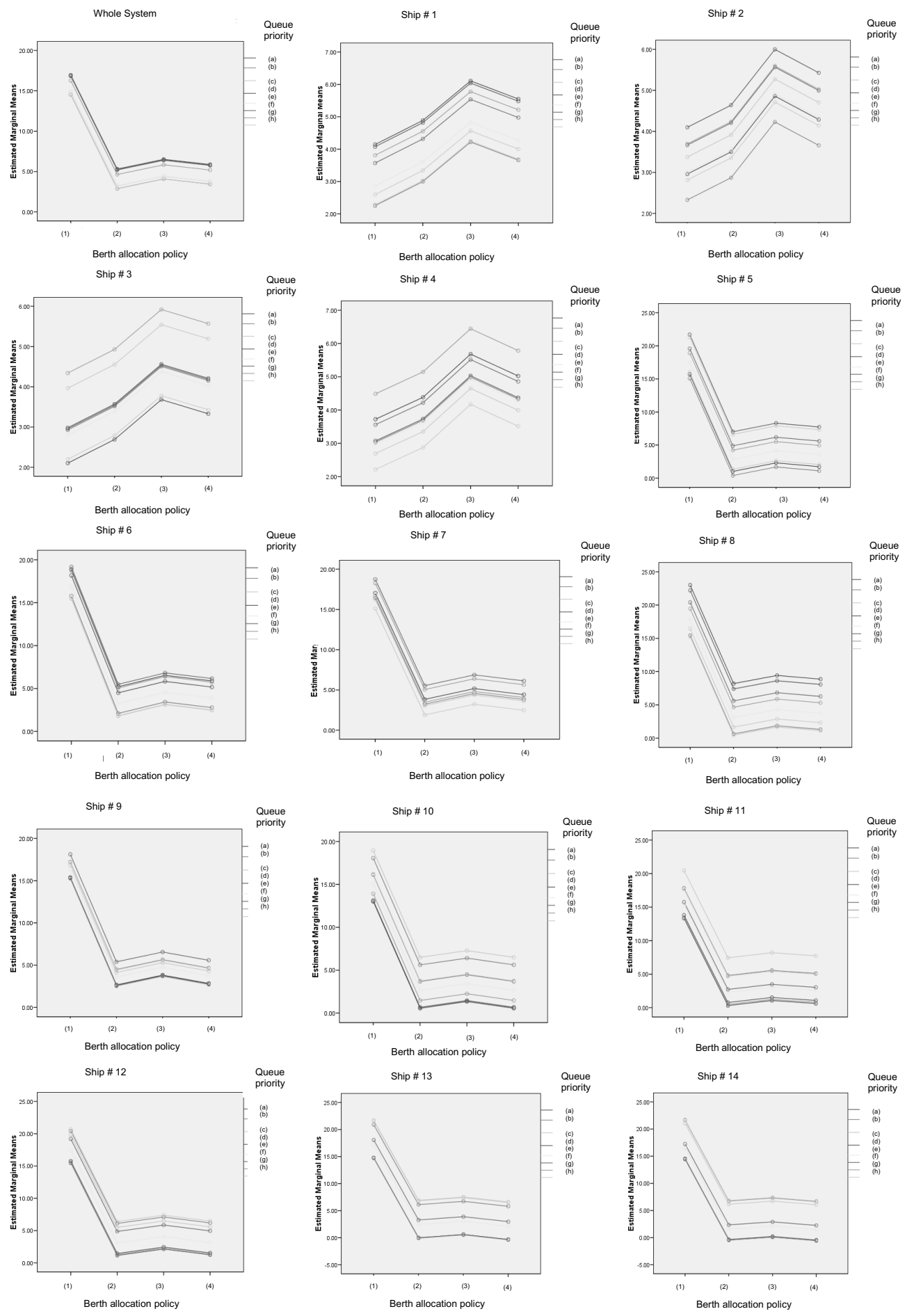

Figure 6 - Estimated marginal means for the variance of the waiting time in queue. 
main properties. Its probability density function is skewed to the right, and for fixed $\beta$ (scale factor) the tail becomes heavier as $\alpha$ (shape factor) increases. Also, the gamma distribution is related to several other distributions, thus making this analysis more robust. Let $W_{q}$ be a gamma waiting time in queue with parameters $\alpha$ and $\beta$. Some important relationships are given next (Zwillinger \& Kokosa, 2000): (i) if $\alpha=1$ and $\beta=1 / \lambda$, then $W_{q}$ has an Exponential distribution with parameter $\lambda$; (ii) if $\alpha=v / 2$ and $\beta=2$, then $W_{q}$ has a Chi-square distribution with $v$ degrees of freedom; (iii) if $\alpha=n$ is an integer, then $W_{q}$ has an Erlang distribution with parameters $\beta$ and $n$; and (iv) as $\alpha \rightarrow \infty, W_{q}$ tends to a Normal distribution with parameters $E\left(W_{q}\right)=\alpha \cdot \beta$ and $\operatorname{var}\left(W_{q}\right)=\alpha \cdot \beta^{2}$.

With respect to the determination of the conditional expected demurrage for the gamma waiting time in queue, Tyworth et al. (1996) and Tyworth \& Ganeshan (2000) presented less complicated solutions, originally applied to inventory management theory, that did not require the use of tabulated values. They demonstrated the relative simplicity of these solutions and discussed some practical considerations as regards to their implementation in electronic spreadsheets, like MS-Excel. In their analytical form and as a spreadsheet function, these solutions are, respectively, given by:

$$
E\left(W q_{i} / W q_{i}>W q_{-} \text {critical }\right)=\int_{W q_{-} \text {critical }}^{\infty}\left(W q_{i}-W q_{-} \text {critical }\right) \cdot g\left(W q_{i}\right) \cdot d W q_{i},
$$

and

$$
\begin{gathered}
E\left(W q_{i} / W q_{i}>W q_{\text {_critical }}\right)=\alpha_{i} \cdot \beta_{i} \cdot\left(1-G A M M A D I S T\left(W q_{\text {_critical }}, \alpha_{i}+1,\right.\right. \\
\left.\left.\beta_{i}, T R U E\right)\right)-W q_{\text {_critical }} \cdot\left(1-G A M M A D I S T\left(W q_{\text {_critical }}, \alpha_{i}, \beta_{i}, T R U E\right)\right),
\end{gathered}
$$

where:

$g\left(W q_{i}\right)=$ the gamma probability density function of $W q_{i}$,

$\alpha_{i} \cdot \beta_{i}=E\left(W q_{i}\right)$, the average waiting time in queue for ship $i$,

$\alpha_{i} \cdot \beta_{i}^{2}=\operatorname{Var}\left(W q_{i}\right)$, the variance of waiting time in queue for ship $i$, and

TRUE $=$ a switch to indicate that the cumulative distribution function is desired.

Different levels of $W q$ critical were simultaneously tested with different levels of demurrage cost ratios. The demurrage cost ratio indicates how many times the demurrage cost per hour of a large ship is greater than the demurrage cost per hour of a small ship. The $T D C$ was calculated for each one of the combinations of berth allocation policies and queue priorities. For each pair of $W q_{-}$critical and demurrage cost ratio, the best combination was then identified and plotted in Figure 7. The coefficient of variation of processing time used was 0.175 .

From Figure 7, one realizes that, when the Wq_critical is low (that is, the waiting time spent in queue is a critical component of the service provided by ports) and the demurrage cost ratio is also low (that is, the demurrage cost for a small ship is greater than the one for a large ship), port authorities should allocate ships to the berth with the smallest queue time and assign priority to the ship with the smallest processing time. In this case, a clear priority would be given to small 


\begin{tabular}{|c|c|c|c|c|c|c|c|c|c|c|c|c|c|c|c|}
\hline & \multicolumn{14}{|c|}{ Demurrage cost ratio between large ships and small ships } \\
\hline & & 0.10 & 0.25 & 0.50 & 0.75 & 1.00 & 2.00 & 3.00 & 4.00 & 5.00 & 6.00 & 7.00 & 8.00 & 9.00 & 10.00 \\
\hline & 1 & & & & & & & & & & & & & & \\
\hline & 2 & & & & & & & & & & & & & & \\
\hline & 4 & & & & & & & & & & & & & & \\
\hline & 6 & & & & & & & & & & & & & & \\
\hline \multirow{11}{*}{ 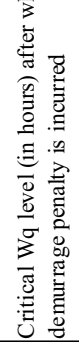 } & 8 & & & & & & & & & & & & & & \\
\hline & 10 & & & & & & & & & & & & & & \\
\hline & 12 & & & & & & & & & & & & & & \\
\hline & 14 & & & & & & & & & & & & & & \\
\hline & 16 & & & & & & & & & & & & & & \\
\hline & $\frac{18}{30}$ & & & & & & & & & & & & & & \\
\hline & 22 & & & & & & & & & & & & & & \\
\hline & 24 & & & & & & & & & & & & & & \\
\hline & 26 & & & & & & & & & & & & & & \\
\hline & & & & & & & & & & & & & & & \\
\hline & 30 & & & & & & & & & & & & & & \\
\hline
\end{tabular}

Legend:

\begin{tabular}{|c|c|c|}
\hline & Berth Allocation Policy & Queue Priority \\
\hline & Ships allocated to berth with shortest queue time & Shortest processing time \\
\hline & Ships allocated to berth with shortest queue time & FIFO \\
\hline & Single queue distributes ships to first available berth & Largest \# Ships Arrivals per year \\
\hline
\end{tabular}

Figure 7 - Best combination in terms of demurrage costs.

ships, so as to favor the cost performance of the port system as a whole. Ships numbers 5 and 8 would be exceptions, since they are large ships with short processing times.

When the demurrage cost ratio increases, but the $\mathrm{Wq}$ _critical is still low, port authorities should adopt a single queue in order to distribute ships to the first available berth. Priority, however, should be assigned to the ships with the largest number of visits per year. Under this criterion, large ships with large number of visits per year would be favored, thus contributing to reduce the total demurrage cost of the system. Ships numbers 6,7 , and 8 meet this criterion.

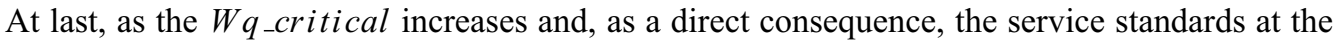
port become less rigorous, the system quickly moves to the classic FIFO discipline, with ships being allocated to the berth with the smallest expected queue time at the moment of their arrival. It seems to be a trade-off between the $W q_{\text {_critical }}$ and the demurrage cost ratio. The higher the $W q_{-}$critical, the smaller the impact of the demurrage cost ratio on the determination of the most adequate policy combination.

Results presented in Figure 7 address the research questions 4 and 5, and indicate the contradictions with respect to the aggregate results in Table 3. If these aggregate results were considered for the purpose of decision-making, no matter the levels of $W q_{-}$critical and the demurrage cost ratios, the combination adopted would be the one with a single queue distributing ships to the first available berth and priorities being assigned to ships with the shortest processing time. One may easily note that this combination is a mixture of the three other combinations depicted in Figure 7, since the specifics of each ship operation are not being considered in the SBL problem. 


\section{CONCLUSIONS}

The SBL problem is complex, because of the different sizes of ships, different interarrival times, and different processing times at berths. By means of a simulation of a two-berth container terminal, developed in ARENA, this case study assesses the impact of different berth allocation policies and queue priorities on the waiting time spent in queue and on total demurrage costs. This paper deals with theory and practical decision-making. In comparison with previous literature, two elements, detailed next, constitute its contribution.

The first element is the simultaneous consideration of four different possible berth allocation policies in parallel to eight possible queue priorities. By means of simulation, this study provides experimental confirmation of the available evidence in literature on the queue priority assignment to ships with the shortest processing time, so as to improve the overall performance of the port, in terms of expected waiting time in queue.

The second element is the incorporation of the demurrage cost for each type of ship to determine the most adequate combination of berth allocation policies and queue priorities. The outputs of the simulation, generated for each ship, are further analyzed and weighted in terms of demurrage probabilities and costs in order to deal with the apparent contradictions between analyzing the SBL operation as a whole and the SBL operation as a weighted sum of the specifics of each ship.

A limitation of this study is related mainly to the underlying assumptions adopted at the design and execution of the experiments: the choice of berthing one ship rather than another into one specific berth is considered not to impact the distance to the location point of its containers in the yard; the impact of the number of lifts and quay cranes is considered to be embedded within the average processing times for each ship; and it is also considered that the scope of the SBL operation modelled in ARENA does not impact the time spent in queue by each ship. Another limitation is related to the small size of the terminal studied, thus making it more difficult to generalize the conclusions generated to larger operations.

Nevertheless, despite such limitations, the simplified model and assumptions in this case study have the advantage of allowing an in-depth understanding of the primary effects of berth allocation and queue priority on port performance and their impact on total demurrage costs. Future research should be conducted under less restrictive assumptions.

\section{REFERENCES}

[1] Alderton P. 2008. Port management and operations. London, Informa.

[2] Asperen EV, Dekker R, Polman M \& Arons HS. 2003. Allocation of ships in a port simulation. Proceedings of the $15^{\text {th }}$ European Simulation Symposium, ISBN: 3-936150-29-X (CD).

[3] Canonaco P, Legato P, Mazza RM \& Musmanno R. 2008. A queuing network model for the management of berth crane operations. Computers \& Operations Research, 35: 2432-2446.

[4] CASACA ACP. 2005. Simulation and the lean port environment. Maritime Economics \& Logistics, 7: $262-280$. 
[5] ChANG YF. 2005. Analysis of operations at the Kaohsiung port new mega container terminal. The Business Review, 4: 123-128.

[6] Chin A \& Tongzon J. 1998. Maintaining Singapore as a major shipping and air transport hub. In: Toh T (Ed.), Competitiveness of the Singapore Economy. Singapore University Press, Singapore, pp. 83-114.

[7] Chung CA. 2004. Simulation Modeling Handbook: a Practical Approach. CRC Press, Boca Raton.

[8] DAsGupta A \& Ghosh M. 2000. Inducing performance in a queue via prices: the case of a riverine port. Management Science, 46: 1466-1484.

[9] Demirci E. 2003. Simulation modelling and analysis of a port investment. Simulation, 79: 94-105.

[10] Dragovic B, Park NK, Radmilovic Z \& Maras V. 2005. Simulation modelling of ship-berth link with priority service. Maritime Economics \& Logistics, 7: 316-355.

[11] Duinkerken MB, Dekker R, Kurstjens StGl, Ottjes JA \& Dellaert NP. 2006. Comparing transportation systems for inter-terminal transport at the Maasvlakte container terminals. $O R$ Spectrum, 28: 469-493.

[12] Fleury PF \& HijJar MF. 2008. Logistics overview in Brazil 2008. Accessed at http://www.ilos.com.br/index2.php?option=com_docman\&task=doc_view\&gid=31\&Itemid=44.

[13] Hair JF, Anderson RE \& TAtham RL. 1998. Multivariate data analysis. Prentice Hall, New York.

[14] HANSEN JB. 1972. Optimizing ports through computer simulation: sensitivity analysis of pertinent parameters. Operations Research Quarterly, 23: 519-530.

[15] Ho MW \& Ho KH. 2006. Risk management in large physical infrastructure investments: the context of seaport infrastructure development and investment. Maritime Economics \& Logistics, 8: $140-168$.

[16] Imai A, Nishimura E \& Papadimitrou S. 2001. The dynamic berth allocation problem for a container port. Transportation Research Part B, 35: 401-417.

[17] Imai A, Sun X, Nishimura E \& Papadimitrou S. 2005. Berth allocation in a container port: using a continuous location space approach. Transportation Research part B, 39: 199-221.

[18] Kim KH, Lee KM \& Hwang H. 2003. Sequencing delivery and receiving operations for yard cranes in port container terminals. International Journal of Production Economics, 84: 283-292.

[19] Legato P \& MAZzA RM. 2001. Berth planning and resources optimization at a container terminal via discrete event simulation. European Journal of Operational Research, 133: 537-547.

[20] Luo M \& Grigalunas T. 2003. A spatial-economic multimodal transportation simulation model for US coastal container ports. Maritime Economics \& Logistics, 5: 158-178.

[21] Meisel F \& Bierwirth C. 2009. Heuristics for the integration of crane productivity in the berth allocation problem. Transportation Research Part E, 45: 196-209.

[22] Nahmias S. 2001. Production and Operations Analysis. McGraw-Hill, New York.

[23] Nishimura E, Imai A \& Papadimitriou S. 2001. Berth allocation planning in the public berth system by genetic algorithms. European Journal of Operational Research, 131: 282-292. 
[24] Ottjes JA, Veeke HPM, Duinkerken MB, Rijsenbrij JC \& Lodewijks G. 2006. Simulation of a multiterminal system for container handling. OR Spectrum, 28: 447-468.

[25] Pachakis D \& Kiremidjian AS. 2003. Ship traffic modeling methodology for ports. Journal of Waterway, Port, Coastal and Ocean Engineering, 129: 193-202.

[26] Parola F \& Sciomachen A. 2005. Intermodal container flows in a port system network: analysis of possible growths via simulation models. International Journal of Production Economics, 97: $75-88$.

[27] SÁ N. 2009. Eldorado carioca. Folha de São Paulo, October $13^{\text {th }}$, p. A8.

[28] Shabayek AA \& Yeung WW. 2002. A simulation model for the Kwai Chung container terminal in Hong Kong. European Journal of Operational Research, 140: 1-11.

[29] Silberholz MB, Golden BL \& BAKer EK. 1991. Using simulation to study the impact of work rules on productivity at marine container terminals. Computer \& Operations Research, 18: 433-452.

[30] TABAChNick BG \& Fidell LS. 2001. Using Multivariate Statistics. Allyn and Bacon, Boston.

[31] TAhar MR \& Hussain K. 2000. Simulation and analysis for the Kelang Container Terminal operations. Logistics Information Management, 13: 14-20.

[32] Tongzon J. 1989. The impact of wharfage costs on Victoria's export-oriented industries. Economic Papers, 8: 58-64.

[33] TU YP \& ChAng YF. 2006. Analyses of operations of ditch container wharf and container yard. The Journal of American Academy of Business, 9: 139-146.

[34] TYworth JE \& Ganeshan R. 2000. A note on solutions to the (Q,r) inventory model for gamma lead-time demand. International Journal of Physical Distribution and Logistics Management, 30: 534-539.

[35] Tyworth JE, GuO Y \& GANEShan R. 1996. Inventory control under gamma demand and random lead-time. Journal of Business Logistics, 17: 291-304.

[36] Wilson D \& Purushothaman R. 2003. Dreaming with BRICs: The path to 2050. Global Economic Paper No: 99. Accessed at http://www.gs.com.

[37] Zwillinger D \& Kokosa S. 2000. CRC Standard Probability and Statistics Tables and Formulae. Chapman \& Hall/CRC, Boca Raton. 